\title{
Variably protease-sensitive prionopathy
}

\section{A differential diagnostic consideration for dementia}

\author{
Stella H. Kim, PsyD, Melissa M. Yu, MD, and Adriana M. Strutt, PhD, ABPP
}

Neurology: Clinical Practice April 2019 vol. 9 no. 2 145-151 doi:10.1212/CPJ.0000000000000612

Correspondence

Dr. Strutt

adrianam@bcm.edu

\section{Abstract \\ Purpose of review}

Prion diseases are rare neurodegenerative diseases that are caused by abnormal pathogenic agents and can affect both humans and animals. These diseases are categorized as sporadic, inherited, or acquired by infection. Clinical manifestations include psychiatric symptoms, cognitive impairment, and parkinsonism, which are similar to those of other prion diseases and frontotemporal dementia variants.

\section{Recent findings}

More recently, scientists discovered a new sporadic prion disease called variably protease-sensitive prionopathy.

\section{Summary}

The following case discusses a patient presenting with sudden onset and rapid decline in cognitive, neurobehavioral, and motor functioning and his clinical journey including treatment interventions

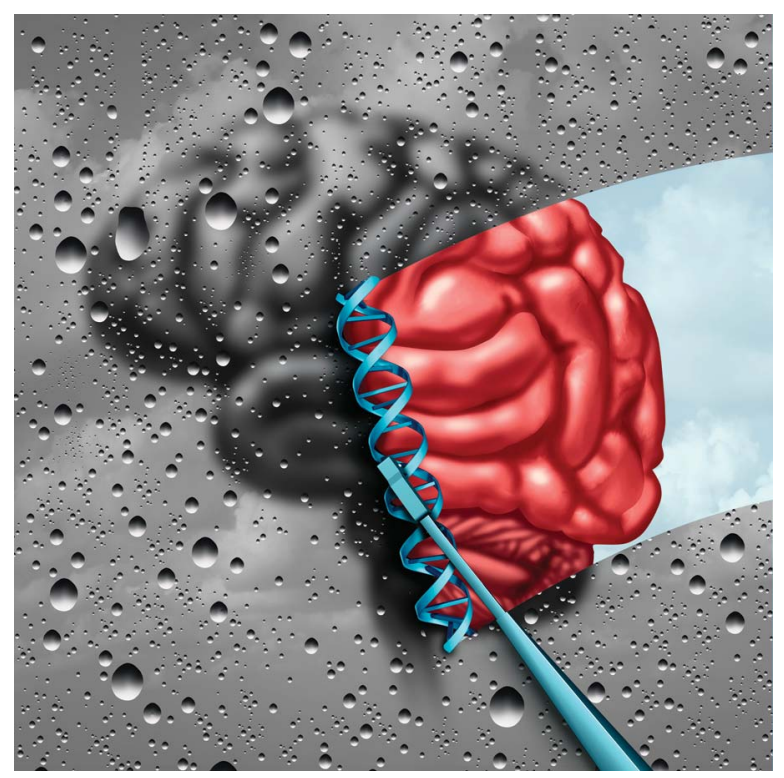
and diagnostic confirmation.

Prion diseases are rare neurodegenerative diseases that are caused when pathogenic agents induce abnormal folding of prion proteins in the brain. ${ }^{1}$ These diseases are categorized as sporadic, inherited, or acquired by infection. ${ }^{2}$ The Centers for Disease Control and Prevention identified the following prion diseases in humans: sporadic Creutzfeldt-Jakob disease (sCJD), variant Creutzfeld-Jakob disease, Gerstmann-Sträussler-Scheinker syndrome (GSS), fatal familial insomnia, and Kuru. The most common prion disease is $\mathrm{SCJD}$, which was discovered in the 1920s and accounts for approximately $90 \%$ of all sporadic prion disease cases with an annual incidence of approximately 2 cases for every 1 million people. ${ }^{2,3}$ According to the Centers for Disease Control and Prevention, diagnostic criteria for probable sCJD consist of rapidly progressive dementia, at least 2 of the 4 clinical features (1) myoclonus, (2) visual/cerebellar signs, (3) pyramidal/extrapyramidal signs, and/or (4) akinetic mutism, and a positive result on at least 1 laboratory test (1) periodic sharp wave complexes on an EEG during the illness, (2) positive 14-3-3 CSF assay if disease duration is less than 2 years, and/or (3) abnormalities in the caudate nucleus and/or putamen on neuroimaging.

More recently, a new sporadic prion disease called variably protease-sensitive prionopathy (VPSPr) was discovered in 11 patients. ${ }^{4,5}$ Since 2008, there is an annual incidence of approximately 2-3 out of 100 million individuals with an average age of onset of 70 years, a 24month survival rate, and a family history of dementia in $30 \%$ of reported cases. ${ }^{2,5-7}$ Clinical 
manifestations include psychiatric symptoms, aphasia and/ or dysarthria, cognitive impairment, ataxia, and parkinsonism. ${ }^{8}$ Although it is categorized as a sporadic prion disease, its phenotypic presentation resembles GSS more than it does sCJD; its clinical profile and slower rate of progression shares features with atypical dementias, and it appears to have a considerably lower rate of human-to-human transmissibility compared with other sCJDs. ${ }^{4,8-10}$

Unfortunately, there are currently no known treatments for VPSPr or other prion diseases. Studies thus far indicate that treatment attempts with various medications have not shown a consistent rate of success. ${ }^{11}$ In addition to nonresponsiveness to medications, there is the challenge of diagnostic clarification to distinguish VPSPr from a nonprion disease because a diagnosis cannot be confirmed until a biopsy or autopsy is completed for clinical, histopathologic, immunohistochemical, and genotypic features. ${ }^{6}$ This is particularly true for VPSPr because it is a relatively new discovery with atypical biological features compared with sCJD, and symptoms that overlap between prion diseases and other neurodegenerative conditions, which has the potential to delay at least symptom management using available treatment methods.

\section{Standard protocol approvals, registrations, and patient consents}

The following information is provided with written consent obtained from the patient's family and approval from the Human Subjects Research Office at Baylor College of Medicine (BCM).

\section{Case description}

The patient is a 51-year-old, right-handed Caucasian man. Medical and psychiatric histories were unremarkable with the exception of a concussion during adolescence without residual sequelae. Surgical history included dental implants (2010). Family medical history was remarkable for dementia of uncertain etiology (maternal uncle and grandmother). The patient reported consuming 1 standard drink every couple of months. He was abstinent from tobacco use for 5 years with a 20-year remote history; illicit substance use was denied. The patient obtained a Bachelor's degree in business and completed 9 hours toward a Master's degree with no reported history of academic difficulties. He worked in janitorial services and subsequently as an administrator in medical facilities for 25 years.

The patient and his wife presented to his community neurologist in July of 2013. His wife reported onset of neurologic and cognitive changes in late May to early June of 2013 with rapid decline over 6 weeks. Specifically, she noted problems with motor functioning, balance, short-term memory, speech, vivid dreams, and dream enactment behaviors. The patient was reportedly involved in a motor vehicle accident in June of 2013 because of his slowed reaction time to changes in driving conditions. His wife also noted changes in his personality and behaviors. She reported that he used to be "very patient and calm" but was now "juvenile" in his interactions, quick to anger, short-tempered with his children, and no longer enjoyed leisure activities. She attributed the latter observation to his physical limitations rather than to his mood. They denied acute infections or recent travel surrounding the time of symptom onset. The patient reportedly requested medical leave of absence in August of 2013 because of declines in his thinking skills, and was on short-term disability while his wife worked full-time. His wife reported she would need to go home during lunch time as he eventually came to need constant supervision.

His Montreal Cognitive Assessment score in July of 2013 was $22 / 30$ with points lost on memory and visual-spatial tasks. A workup was ordered to assess for rapidly progressive dementia. Results for MRI and EEG were unremarkable. CSF analysis showed 8 white blood cells (10\% segmented), 169 red blood cells, normal glucose (57), protein (34), and an elevated 14-3-3 protein of 2.3 (normal $<1.5$ ).

The patient and his wife were referred to a neurologist at BCM for a second opinion in September of 2013. His performance on the Mini Mental Status Exam was 25/30. His presentation was remarkable for complaints of ataxia, fasciculations, stooped posture, dysarthria, dysmetria, and difficulty with fine movements. Prominent findings on neurologic examination included frontal reflexes including glabellar tap, jaw jerk, and snout as well as bradykinesia, apraxia with bimanual tasks, dystonic posturing with the right hand, and mildly parkinsonism gait with stooped posture and decreased arm swing.

Differential diagnoses included sCJD and frontotemporal dementia with parkinsonism (FTDP-17 variant). The patient was prescribed Aricept in an attempt to aid his memory, a repeat CSF study was ordered, and was referred for a neuropsychological evaluation. A chronological summary of his medical visits, relevant clinical findings, and the course of his neurologic motor symptoms 2 months after his initial visit is provided in table 1 .

\section{Neuropsychological assessment}

A comprehensive neuropsychological battery was administered to assess the cognitive domains of premorbid intellect, attention/concentration, processing speed, executive functioning, language, memory, visual-perception, and motor functioning (table 2). Additional information was collected from self and informant-report questionnaires (table 3), available medical records, and clinical interview with the patient and his wife.

The patient was accompanied to the evaluation by his wife and father. He was tested in 2 outpatient sessions. He wore reading glasses, was well-groomed, and appropriately dressed. He was 
Table 1 Chronology of clinical findings

\begin{tabular}{|c|c|c|c|c|}
\hline Date of visit & Provider & $\begin{array}{l}\text { Laboratory work and/or } \\
\text { neuroimaging results }\end{array}$ & Physical symptoms & $\begin{array}{l}\text { Cognitive and/or neurobehavioral } \\
\text { symptoms }\end{array}$ \\
\hline July 2013 & Community provider & $\begin{array}{l}\text { Brain MRI with contrast: Normal } \\
\text { reading, increased T2 signal in } \\
\text { bilateral mesial temporal regions that } \\
\text { may be due to artifact }\end{array}$ & Motor and balance & $\begin{array}{l}\text { Short-term memory, speech, and } \\
\text { confusion }\end{array}$ \\
\hline \multirow[t]{3}{*}{ August 2013} & Community provider & Hospitalized for IVIGa treatment & Motor and balance & $\begin{array}{l}\text { Short-term memory, speech, and } \\
\text { confusion }\end{array}$ \\
\hline & & Initiated physical therapy & & \\
\hline & & $\begin{array}{l}\text { Lumbar puncture: Slight elevation in } \\
\text { CSF protein } 14-3-3(2.3 \text {; normal }<1.5)\end{array}$ & & \\
\hline September 2013 & BCM neurology & $\begin{array}{l}\text { Referral for neuropsychological } \\
\text { evaluation }\end{array}$ & Motor and balance & $\begin{array}{l}\text { Incomplete sentences, paraphasic } \\
\text { errors, forgetfulness, and difficulty } \\
\text { learning new material }\end{array}$ \\
\hline September 2013 & BCM neuropsychology & See tables 2 and 3 & Motor and balance & $\begin{array}{l}\text { Short-term memory, attention, and } \\
\text { word-retrieval }\end{array}$ \\
\hline \multirow[t]{2}{*}{ October 2013} & BCM neurology & $\begin{array}{l}\text { Repeat lumbar puncture: WNL for CSF } \\
\text { protein 14-3-3 }\end{array}$ & Motor and balance & $\begin{array}{l}\text { Short-term memory, sun downing, } \\
\text { hallucinations }\end{array}$ \\
\hline & & $\begin{array}{l}\text { PET scan with decreased activity in } \\
\text { frontal and parietal lobes more } \\
\text { consistent with Alzheimer's disease }\end{array}$ & & \\
\hline January 2014 & Community provider & & Incontinence, frequent falls & $\begin{array}{l}\text { Wandering, sun downing, } \\
\text { hallucinations, fixates on random } \\
\text { ideas, impaired auditory } \\
\text { comprehension }\end{array}$ \\
\hline
\end{tabular}

Abbreviation: $\mathrm{BCM}=$ Baylor College of Medicine; IVIG = intravenous immunoglobulin; WNL = within normal limits.

alert and fully oriented with the exception of the date. Speech was generally coherent and goal-directed but limited. Ability to follow directions was mildly decreased at times and attention/ concentration fluctuated. His responses were preservative at times and he evidenced poor insight regarding his areas of cognitive weakness. Mood was euthymic and affect varied. He intermittently evidenced a fixed gaze with a slowed response rate, and occasional jovial and disinhibited behaviors were observed that were atypical for someone his age. He was cooperative throughout testing, and testing results were considered to be a valid estimate of his neuropsychological status as his performance on validity measures was grossly within normal limits.

\section{Neuropsychological summary and impression}

Basic orientation was grossly intact and general mental status was below expectation. Relative to his estimated average premorbid level of functioning based on a single-word reading task, cognitive testing revealed borderline impaired to deficient scores on measures of auditory attention, processing speed, setshifting, response inhibition, visual planning/organization, general fund of knowledge, naming, verbal fluency, auditory comprehension of complex commands, repetition, visuospatial abilities, and praxis. Scores were within normal limits (i.e., low average to high average) for auditory comprehension of basic commands, abstract verbal reasoning, and novel problemsolving with variable memory. Specifically, his ability to encode, retrieve, and recognize contextual verbal information was intact. Although his retrieval was impaired, his ability to encode and recognize unstructured verbal information was also preserved. Visual memory was intact for basic geometric shapes but impaired for more complex visual stimuli; however, the latter was due to poor visual-motor integration and executive dysfunction rather than a reflection of visual memory.

On self-report questionnaires, he endorsed a mild level of symptoms of depression and denied frontal lobe-mediated behaviors. On an informant questionnaire regarding neurobehavioral symptoms, his wife endorsed observing depression, anxiety, disinhibition, irritability, night-time behaviors, (i.e., waking up at night and asking, "Where's the shaving cream?"), and a change in appetite because of changes in food texture preference. The apathy, disinhibition, and executive dysfunctions scales were within normal limits on a questionnaire assessing frontal lobe-mediated behaviors; however, interim change scores pre-disease and post-disease were clinically meaningful in comparison to age-matched and sex-matched peers. Regarding his functional status, his wife endorsed declines in the patient's physical self-maintenance skills (i.e., assistance required for food preparation, dressing and grooming, bathing, and ambulation) and instrumental activities (i.e., financial management, shopping, and transportation because he discontinued driving in June of 2013 after a motor vehicle accident). 
Table 2 Summary of neurocognitive measures and performance

\begin{tabular}{|c|c|c|}
\hline Targeted domain & Measure & Clinical classification \\
\hline \multirow[t]{3}{*}{ Motivation/effort } & $\begin{array}{l}\text { Test of Memory Malingering (TOMM; Trial 1, Trial 2, \& } \\
\text { Retention) }\end{array}$ & Pass across all trials \\
\hline & Rey-15 & Pass \\
\hline & Reliable Digit Span & Pass \\
\hline General mental status & Montreal Cognitive Assessment & 20/30; 5/6 with incorrect date that was off by 1 \\
\hline Premorbid level of functioning & Wechsler Test of Adult Reading (WTAR) & Average \\
\hline $\begin{array}{l}\text { General intellectual } \\
\text { functioning }\end{array}$ & $\begin{array}{l}\text { Wechsler Adult Intelligence Scale-4th Edition (WAIS-IV } \\
\text { subtest: Information) }\end{array}$ & Borderline impaired \\
\hline \multirow[t]{2}{*}{ Attention/concentration } & $\begin{array}{l}\text { Wechsler Adult Intelligence Scale-4th Edition (WAIS-IV } \\
\text { subtests: Digit Span) }\end{array}$ & Borderline impaired \\
\hline & Verbal Sustained Attention Test (VSAT) & Deficient for speed and accuracy \\
\hline \multirow[t]{2}{*}{ Information processing speed } & Trail Making Test $\mathrm{A}$ & Borderline impaired \\
\hline & Symbol Digit Modalities Test (oral) & Deficient \\
\hline \multirow[t]{5}{*}{ Executive functioning } & Stroop Color-Word Test & Deficient \\
\hline & Trail Making Test B & Deficient with 3 errors \\
\hline & $\begin{array}{l}\text { Wechsler Adult Intelligence Scale-4th Edition (WAIS-IV } \\
\text { subtest: Similarities) }\end{array}$ & Average \\
\hline & Controlled Oral Word Association Test & Borderline impaired \\
\hline & Wisconsin Card-sorting Test-64 Card Version (WCST-64) & $\begin{array}{l}\text { Low average ( } 1 \text { category) with deficient perseverative } \\
\text { errors }\end{array}$ \\
\hline \multirow[t]{2}{*}{ Verbal memory } & $\begin{array}{l}\text { Wechsler Memory Scale, 4th Edition (WMS-IV subtest: } \\
\text { Logical Memory) }\end{array}$ & Average, average, high average \\
\hline & Hopkins Verbal Learning Test, Revised (HVLT-R) & Low average, borderline, average (12/12 with $1 \mathrm{FP}$ error) \\
\hline \multirow[t]{3}{*}{ Visual memory } & $\begin{array}{l}\text { Wechsler Memory Scale, Revised (WMS-R subtest: Visual } \\
\text { Reproduction) }\end{array}$ & Low average, low average \\
\hline & $\begin{array}{l}\text { Wechsler Memory Scale, Revised (WMS-R subtest: } \\
\text { Designs) }\end{array}$ & Low average and average \\
\hline & Rey-Osterrieth Complex Figure Test & Deficient across all 3 trials \\
\hline \multirow[t]{4}{*}{ Language } & Boston Naming Test (BNT) & Deficient; paraphasic errors and neologisms \\
\hline & Animal fluency & Deficient \\
\hline & Sentence repetition & Impaired \\
\hline & $\begin{array}{l}\text { Western Aphasia Battery subtests: } \mathrm{Y} / \mathrm{N} \text { and sequential } \\
\text { Commands }\end{array}$ & Generally intact; impaired \\
\hline \multirow[t]{3}{*}{ Visual-perceptual } & $\begin{array}{l}\text { Beery-Buktenica Developmental Test of Visual-Motor } \\
\text { Integration, 5th Edition (VMI) }\end{array}$ & Deficient \\
\hline & Clock drawing & Impaired on command and on copy \\
\hline & $\begin{array}{l}\text { Wechsler Adult Intelligence Scale-4th Edition (WAIS-IV } \\
\text { subtest: Block design) }\end{array}$ & Borderline impaired \\
\hline Motor functioning & Apraxia examination & $\begin{array}{l}\text { Buccofacial intact; mild left-sided intransitive and } \\
\text { transitive apraxia with lower extremity motor overflow } \\
\text { when asked to engage in upper extremity motor testing }\end{array}$ \\
\hline
\end{tabular}

Abbreviation: $\mathrm{FP}=$ False positive.

In summary, the patient's neuropsychological profile was not consistent with a typical Alzheimer disease $(\mathrm{AD})$ profile because his performance on memory measures was grossly intact. Findings revealed both cortical and subcortical frontal areas of cognitive impairment in conjunction with mild frontal lobe-mediated behavioral changes based on self-report and 
informant-report questionnaires. This evaluation was intended to serve as a baseline with a recommendation made for follow-up testing for interim changes and further diagnostic clarification.

\section{Follow-up visits}

The patient and his wife met with his BCM neurologist after the neuropsychological evaluation. His wife reported functional decline in gait, sun downing, worsening of cognitive and motor function as day progresses, and emotional lability with easy crying. CSF studies showed 6 white blood cells, 1 red blood cell, glucose 74 (normal), protein 33 (normal), and 14-3-3 protein $<1.0$ (normal). A PET scan was ordered and results revealed diminished FDG accumulation in the cortical gray matter involving the temporal and parietal regions, which were thought to be suggestive of possible temporoparietal dementia, such as $\mathrm{AD}$ or $\mathrm{AD}$ with Lewy bodies. Subsequent electronic communications between the neurologist and the patient's wife indicated the patient was rapidly declining, and possible sCJD was considered while other diagnostic possibilities such as paraneoplastic or autoimmune encephalitis were evaluated.

In January of 2014, the patient and his wife met with his community provider. His wife reported increased confusion with wandering, sun downing, hallucinations, and incontinence with a tendency to fixate on random ideas, such as wanting to go to Disneyland and attend college. She reported that he continued to have difficulty walking and frequent falls. The patient had a sitter with him at all times and required assistance for basic and instrumental ADLs. During the physical examination, the neurologist documented observing the patient having difficulty following commands (i.e., put his shoes on the wrong feet). He also repeated the names of his children several times. His neurologist documented that the patient appeared to be declining too rapidly for this to be $\mathrm{AD}$
This case highlights the challenges of differential diagnosis and symptom management of a fatal disease with features overlapping numerous other neurodegenerative conditions.

and requested a repeat PET scan. He was also prescribed 0.5 $\mathrm{mg}$ Risperdal at night for his hallucinations. Subsequent PET scan results were unavailable for review.

The patient's medical records indicated date of death in April of 2014. A brain autopsy was completed by the National Prion Disease Pathology Surveillance Center in July of 2014 by carrying out histopathologic and immunohistochemical examinations, a special Western blot, and sequencing of the coding region of the prion protein $(\operatorname{PrP})$ gene. The results confirmed a diagnosis of prion disease with characteristics of VPSPr that belongs to the subtype VPSPr-129VV.

\section{Additional collateral information}

After his passing, the patient's wife was contacted through phone (July 2017) to review the contents of this manuscript and to obtain written consent for publication. She shared that she had recently reviewed the patient's medical records leading up to his death and came to the realization that his cognitive changes may have begun before June 2013. She recalled observing a decline in his ability to manage their finances, with errors noted around September 2012. She stated this was unusual given his vocational history as an

Table 3 Summary of mood, neurobehavioral symptoms, and functional abilities

\begin{tabular}{|c|c|c|}
\hline Targeted symptomatology & Measure & Clinical classification \\
\hline Depression screening & Beck Depression Inventory, 2nd Edition (BDI-II) & Mild range \\
\hline Anxiety screening & Beck Anxiety Inventory (BAI) & Moderate range \\
\hline \multirow[t]{2}{*}{ Functional independence } & $\begin{array}{l}\text { Lawton and Brody's Physical Self-Maintenance Scale } \\
\text { (PSMS) }\end{array}$ & $\begin{array}{l}\text { Assistance with food preparation, dressing and } \\
\text { grooming, getting in and out of the bathtub to shower, } \\
\text { ambulation }\end{array}$ \\
\hline & $\begin{array}{l}\text { Lawton and Brody's Independent Activities of Daily Living } \\
\text { Scale (IADLS) }\end{array}$ & $\begin{array}{l}\text { Requires assistance with transportation, shopping, } \\
\text { purchase, and financial management }\end{array}$ \\
\hline $\begin{array}{l}\text { Neuropsychiatric symptoms } \\
\text { secondary to dementia }\end{array}$ & Neuropsychiatric Inventory Questionnaire (NPI-Q) & $\begin{array}{l}\text { Depression, anxiety, disinhibition, irritability, nighttime } \\
\text { behaviors (waking up and wanting to start his routine), } \\
\text { change in appetite (changes in food texture preference); } \\
\text { moderate to severe familial emotional distress }\end{array}$ \\
\hline \multirow[t]{2}{*}{$\begin{array}{l}\text { Frontal lobe-mediated skills } \\
\text { and behaviors }\end{array}$} & Frontal Systems Behavior Scale (FrSBe)—Self-rating form & $\begin{array}{l}\text { Denied any pre- and post-disease problems with apathy, } \\
\text { disinhibition, and executive dysfunction }\end{array}$ \\
\hline & $\begin{array}{l}\text { Frontal Systems Behavior Scale (FrSBe)_Family rating } \\
\text { form }\end{array}$ & $\begin{array}{l}\text { Normative scores were not clinically elevated, within normal } \\
\text { limits compared with age-matched and sex-matched peers; } \\
\text { however, interim changes in apathy, disinhibition, and } \\
\text { executive dysfunction were clinically meaningful. }\end{array}$ \\
\hline
\end{tabular}


administrator. The patient's wife also reported remembering out of character personality and behavioral changes that were directed toward his work staff. She stated that his management skills at work used to be described as fair as he maintained appropriate interpersonal boundaries with his employees; later, he reportedly began to yell and show poor frustration tolerance. As he continued to evidence cognitive decline, his wife reported that he eventually referred to himself in the third person.

\section{Discussion}

This case highlights the challenges of differential diagnosis and symptom management of a fatal disease with features overlapping numerous other neurodegenerative conditions. The patient demonstrated sudden onset and rapid decline in cognitive, psychiatric, and motor functioning within approximately 11 months. As previously mentioned, the combination of cognitive deficits and parkinsonism features can be seen in prion diseases such as VPSPr, GSS, and sCJD. This phenotypic profile can also be seen in an uncommon subtype of frontotemporal dementia.

FTD is a neurodegenerative disease with a heterogeneous presentation that may include parkinsonism due to mutations in the genes that encode microtubule-associated protein tau and progranulin (PGRN). ${ }^{12} \mathrm{~A}$ lesser known frontotemporal subtype with parkinsonism, referred to as FTDP-17 due to its association with PGRN mutations in chromosome 17, is a form of dementia that was first defined and presented in $1996 .{ }^{13,14}$ Individuals with FTDP-17 also demonstrate changes in personality, behavior, speech, and executive abilities, including disinhibition, anhedonia, delusions, hallucinations, a decline in functional abilities, and problems with judgment and planning. ${ }^{15}$ Unlike the prion diseases, these individuals typically survive 5-10 years after the time of symptom onset.

As previously noted, a definitive diagnosis of VPSPr cannot be made until a biopsy or autopsy is completed for clinical, histopathologic, immunohistochemical, and genotypic analysis. ${ }^{6}$ A proposed clinical diagnostic criteria for VPSPr consists of the following: (1) cognitive impairment and/or at least 2 additional clinical features (i.e., psychiatric symptoms, parkinsonism, aphasia, ataxia, and/or myoclonus), (2) symptom duration of under 8 years, and (3) absence of alternative etiology or phenotype divergence from atypical neurodegenerative dementias. ${ }^{16}$ Current histopathologic and neurodiagnostic findings associated with VPSPr consist of spongiform encephalopathy, $\operatorname{PrP}$ amyloid plaques, and $\operatorname{PrP}$ deposition, with atrophy noted in the cerebral cortex, basal ganglia, and the cerebellum. ${ }^{16}$ The hippocampi have been generally spared, which is consistent with the patient's cognitive profile of relatively preserved memory. Of the reported case studies thus far, VPSPr has a relatively heterogeneous clinical presentation. There was an isolated case where the patient with VPSPr was treated with doxycycline and was able to extend her
Neuropsychological evaluation may be helpful to clinicians with neuroimaging and laboratory tests in providing a more comprehensive profile and to help potentially rule out differential diagnoses.

life by 5 years while remaining in a state of akinetic mutism. ${ }^{11}$ There has also been an isolated case involving a 93-year-old patient who did not present with the cognitive, psychiatric, or neurologic symptoms associated with VPSPr but was histopathologically diagnosed with this disease postmortem. ${ }^{17}$

Because no disease-modifying treatments currently exist, treatment is typically focused on symptom management. Current research continues to explore potential biomarkers and medications that may assist with earlier detection and slowing of progression, including doxycycline and neurofilament light chain proteins. ${ }^{11,18}$ However, these are isolated studies where underlying mechanisms remain unclear. Neuropsychological evaluation may be helpful to clinicians with neuroimaging and laboratory tests in providing a more comprehensive profile and to help potentially rule out differential diagnoses. For instance, in the case of this patient, one of the differential diagnoses was early-onset $\mathrm{AD}$. His neuropsychological profile revealed that his pattern of cognitive strengths and weaknesses were not consistent with an $\mathrm{AD}$ profile. Therefore, although no further diagnostic clarification could be made as the evaluation was intended to be used as a baseline, the findings could be integrated with his laboratory and neuroimaging results to further guide his medication regimen and future planning.

\section{Author contributions}

S. H. Kim: drafting/revising the manuscript and analysis or interpretation of data. M. M. Yu: drafting/revising the manuscript and acquisition of data. A. Strutt: drafting/revising the manuscript, data acquisition, and study concept or design.

\section{Acknowledgment}

The authors thank the patient's wife, two sons, and daughter for their participation in this case study.

\section{Study funding}

No targeted funding reported.

\section{Disclosure}

The authors report no disclosures relevant to the manuscript. Full disclosure form information provided by the authors is available with the full text of this article at Neurology.org/cp. 


\section{Publication history}

Received by Neurology: Clinical Practice June 27, 2018. Accepted in final form September 27, 2018.

\section{References}

1. Centers for Disease Control and Prevention (CDC). CDC's Diagnostic Criteria for Creutzfeldt-Jakob Disease (CJD). Available at: cdc.gov/prions/cjd/diagnostic-criteria.html. Accessed February 11, 2015.

2. Puoti G, Bizzi A, Forloni G, Safar JG, Tagliavini F, Gambetti P. Sporadic human prion diseases: molecular insights and diagnosis. Lancet Neurol 2012;11: 618-628.

3. Parchi P, Strammiello R, Giese A, Kretzschmar H. Phenotypic variability of sporadic human prion disease and its molecular basis: past, present, and future. Acta Neuropathologica 2011;121:91-112.

4. Diack $\mathrm{AB}$, Ritchie $\mathrm{DL}$, Peden $\mathrm{AH}$, et al. Variably protease-sensitive prionopathy, a unique prion variant with inefficient transmission properties. Emerg Infect Dis 2014; 20:1969-1979.

5. Zou WQ, Puoti G, Xiao X, et al. Variably protease-sensitive prionopathy: a new sporadic disease of the prion protein. Ann Neurol 2010;68:162-172.

6. Gambetti P, Dong Z, Yuan J, et al. A novel human disease with abnormal prion protein sensitive to protease. Ann Neurol 2008;63:697-708.

7. Bonda DJ, Manjila S, Mehndiratta P, et al. Human prion diseases: surgica lessons learned from iatrogenic prion transmission. Neurosurg Focus 2016;41: E10.
8. Gambetti P, Puoti G, Zou WQ. Variably protease-sensitive prionopathy: a novel disease of the prion protein. J Mol Neurosci 2011;45:422-424.

9. Notari S, Xiao X, Espinosa JC, et al. Transmission characteristics of variably proteasesensitive prionopathy. Emerg Infect Dis 2014;20:2006-2014.

10. Zou WQ, Gambetti P, Xiao X, Yuan J, Langeveld J,, Pirisinu L. Prions in variably protease-sensitive prionopathy: an update. Pathogens 2013;2:457-471.

11. Assar H, Topakian $\mathrm{R}$, Weis $\mathrm{S}$, et al. A case of variably protease-sensitive prionopathy treated with doxycycline. J Neurol Neurosurg Psychiatry 2018;86:816-818.

12. Baizabal-Carvallo JF, Jankovic J. Parkinsonism, movement disorders and genetics in frontotemporal dementia. Nat Rev Neurol 2016;12:175-185.

13. Foster NL, Wilhelmsen K, Sima AA, Jones MZ, D’Amato CJ, Gilman S. Frontotemporal dementia and parkinsonism linked to chromosome 17: a consensus conference. Ann Neurol 1997;41:706-715

14. Baker M, Mackenzie IR, Pickering-Brown SM, et al. Mutations in progranulin cause tau-negative frontotemporal dementia linked to chromosome 17. Nature $2006 ; 442$ : 916-919.

15. Wszolek ZK, Kardon RH, Wolters EC, Pfeiffer RF. Frontotemporal dementia and parkinsonism linked to chromosome 17 (FTDP-17). Mov Disord 2016;16: $756-760$

16. Notari S, Appleby BS, Gambetti P. Variably protease-sensitive prionopathy. Handb Clin Neurol 2018;153:175-190.

17. Ghoshal N, Perry A, McKeel D, et al. Variably protease-sensitive prionopathy in an apparent cognitively normal 93 year old. Alzheimer Dis Assoc Disord 2015;29: 173-176.

18. Abu-Rumeileh S, Capellari S, Stanzani-Maserati M, et al. The CSF neurofilament light signature in rapidly progressive neurodegenerative dementias. Alzheimer's Res Ther 2018;10:3.

\section{Subspecialty Alerts by E-mail!}

Customize your online journal experience by signing up for e-mail alerts related to your subspecialty or area of interest. Access this free service by clicking on the "My Alerts" link on the home page. An extensive list of subspecialties, methods, and study design choices will be available for you to choose from-allowing you priority alerts to cutting-edge research in your field! 